\title{
O INTERVENCIONISMO HÍBRIDO E A AUTONOMIA DO BANCO CENTRAL DO BRASIL
}

HYBRID INTERVENTIONISM AND THE AUTONOMY OF BANCO CENTRAL DO BRASIL

\section{Daniel Augusto Arouca Bizzotto* Lorena Ribeiro de Carvalho Sousa**}

\begin{abstract}
Resumo
Em meio ao debate político-eleitoral brasileiro surgiu um tema pouco estudado e debatido nos meios acadêmicos brasileiros, a autonomia do Banco Central. Trata-se de uma agência reguladora do sistema bancário nacional? Quais seriam os resultados de sua autonomia em uma Economia que ainda busca se consagrar como a sétima em âmbito mundial? São perguntas do cotidiano que merecem uma atenção maior ao que tem se dado, visto que o Banco Central se tornou panaceia de uma esquizofrênica corrida eleitoral.
\end{abstract}

Palavras-chave: Banco Central. Agência reguladora. Autonomia. Intervencionismo híbrido.

\begin{abstract}
Amid the Brazilian political-electoral debate a topic little studied and debated in Brazilian academia, the autonomy of the Central Bank emerged. It is a regulatory agency of the national banking system? What were the results of their autonomy in an Economy that still seeks to enshrine as seventh worldwide? Are everyday questions that deserve closer attention to what has occurred since the Central Bank became panacea of a schizophrenic election race.
\end{abstract}

Keywords: Central Bank. Regulatory agency. Autonomy. Hybrid interventionism.

\section{INTRODUÇÃO}

A regulação de um determinado domínio econômico suscita, indubitavelmente, ao assunto intervenção do Estado no domínio econômico. Referida atuação estatal se faz presente

Artigo submetido em 09 de junho de 2020 e aprovado em 11 de agosto de 2020

\footnotetext{
Mestre em Direito Público pelo Programa de Pós-Graduação em Direito da PUC Minas. Email: profbizzottomono@gmail.com.

Mestra em Direito Processual pelo Programa de Pós-Graduação em Direito da PUC Minas. Email: lorena.ribeirocs@gmail.com
} 
desde o Absolutismo. Essa época foi marcada pela economia mercantilista, baseada no cunho da moeda e em investimentos em grandes navegações para descoberta de novas fronteiras. Observava-se forte ação do Estado no mercado. Na Política, os reis detinham todo o poder em suas mãos e em seus governos era significativa a confusão entre o interesse público com o privado. O capital não possuía liberdade. Apenas cumpria a função de saciar a sede de poder das autoridades.

Nesses tempos de arbitrariedades a burguesia assumia o comércio e iniciava o exercício do controle do poder econômico. Autores renomados pensavam em um paradigma liberal de Estado. O principal foi Adam Smith, que internalizou a liberdade nas relações econômicas em sua obra A Riqueza das Nações (O’ROURKE, 2008). Toda a luta por liberdade resultou nas denominadas revoluções burguesas. A classe burguesa passou a ter o poder político-econômico. O liberalismo trouxe, para a Política, uma nova forma de governar, descrita no lema da Revolução Francesa "Liberdade, Igualdade e Fraternidade". No campo econômico observava-se uma intervenção enfraquecida, a partir de uma legislação desarticulada e esparsa.

No paradigma liberal de Estado o que se observou foi excessiva concentração de riquezas nas mãos de poucos, direito de propriedade de contratar absolutos e a perenização da igualdade formal. Os burgueses massacravam os trabalhadores para garantirem seus interesses. O capital circulava com ampla e irrestrita liberdade.

Mas no início do século XX um evento determinou nova transição paradigmática. A Revolução Russa e a ascensão dos bolcheviques ao poder, formando a União das Repúblicas Soviéticas Socialistas (URSS). O temor dos donos do poder de que o mundo tornar-se um globo vermelho os fez redesenhar o mapa político-econômico sem atrapalhar seus interesses. Nova transição estava por vir.

Com o objetivo de manter o status quo, os governos, estes meros servos do capital, passam a legislar sobre direitos sociais. Para manter o equilíbrio econômico sem deixar de ser economia de mercado surgiram a figura do Estado empresário e normas para regulamentar a atividade econômica, com o objetivo de combater as crises cíclicas do capital. É o advento do Neoliberalismo, no qual se observa, neste primeiro momento, a intervenção estatal planejada, com o objetivo principal de evitar abusos do poder econômico, entre tantos outros motivos. $\mathrm{O}$ Estado regulamentador possui maior aparato, o que facilita a solução de conflitos sociais.

$\mathrm{Na}$ transição de paradigma político-econômico eventos de repercussão mundial ocorreram. Os principais a queda da Bolsa de Nova Iorque e as Duas Grandes Guerras. O 
Capitalismo passava por seu momento de maior turbulência. A vitória dos Aliados ao final da Segunda Grande Guerra impõem ao capital uma nova forma de atuar. As potências capitalistas da época passaram a redefinir o mapa político-econômico. Um novo cenário internacional, estruturado em organizações multilaterais, passou a ser construído. No campo econômico, além da adoção do padrão dólar, em substituição ao padrão ouro, o que se assistiu foi a mudança para o Neoliberalismo, agora em fundamentado em intervenção planejada de regulação. Observa-se o aumento na produção de normas, assim como o seu conteúdo, o que mantém a intervenção indireta.

Este paradigma é denominado de intervencionismo híbrido, com atuação das denominadas agências reguladoras, autarquias que produzem marco regulatório técnicos para determinados domínios econômicos. A técnica de intervenção mudou, mas o instituto foi mantido. Ainda sobre regulação, pode-se afirmar, também, que o Estado se mantém no mercado para contrabalancear a atuação da Iniciativa Privada.

Feita essa reconstrução histórica busca-se, nas próximas linhas analisar as funções da autoridade monetária Banco Central em uma economia de mercado baseado na regulação. E, no momento seguinte, oferecer subsídios técnico-científicos para os debates atuais, quais sejam se o BACEN é, ou não, uma agência reguladora no que implicaria sua autonomia/independência.

\section{A INTERVENÇÃO DO ESTADO NO DOMÍNIO ECONÔMICO}

Neste primeiro momento faz-se necessário analisar o instituto da intervenção do Estado no domínio econômico, a partir de uma interpretação constitucionalizada do assunto. Antes, porém, faz-se necessário delinear as diferenças entre regulamentação e regulação.

A regulamentação, conforme art. 84, IV, § único, Constituição da República de 1988, é atividade exclusiva do Chefe da Função Executiva, não sendo passível de delegação.

Já a regulação é atividade atribuída à entidade reguladora, pode ser vista sob dois prismas. Pelo lado econômico trata-se de conjunto de regras de conduta e de controle de atividade privada do Estado, com a finalidade de estabelecer o funcionamento equilibrado do mercado. Já o lado jurídico é o conjunto de regras de conduta e de controle de atividade econômica, pública e privada, e das atividades sociais não exclusivas do Estado, com a finalidade de proteger o interesse público. Portanto, regulação é todo tipo de intervenção que o Estado faz no domínio econômico público e privado, ora para estudar e orientar o mercado, 
ora para proteger o interesse público. A regulação não exclui a ação estatal no domínio econômico.

O que se pode concluir sobre regulamentação e regulação é que ambas se diferenciam em relação ao tamanho da ação do Estado no domínio econômico. Na regulamentação, o aparato estatal cresce com o surgimento de empresas públicas, sociedades de economia mista, fundações públicas, entre outras entidades estatais. Já na regulação eleva-se a criação de leis para o funcionamento da Economia.

Feita essas primeiras considerações, passa-se a análise das formas de ação do Estado no domínio econômico.

\subsection{A intervenção direta}

A intervenção direta do Estado no domínio econômico é ofensiva, com efeitos imediatos. Traduz a ideia de Estado empresário, com exercício direto da atividade econômica, através de entidades estatais da Administração Indireta, com utilização de capital estatal. Exemplos de referida atuação podem ser vistas no monopólio dos Correios e da Companhia Siderúrgica Nacional, além da concorrência entre Banco do Brasil e Caixa Econômica Federal. A prestação remunerada de serviços públicos e colocação de produtos no mercado pelo Estado também são formas de intervenção direta do Estado no domínio econômico.

A Constituição da República de 1988 impõe requisitos para que o Estado aja diretamente no domínio econômico. Eles estão previstos no art. 173, caput, em que "ressalvados os casos previstos nesta Constituição, a exploração direta de atividade econômica só será permitida quando necessária aos imperativos da segurança nacional ou a relevante interesse coletivo, conforme definidos em lei." (BRASIL, 1988).

Assim, são condições inafastáveis para a ação direta do Estado na economia, que seja através de lei e que respeite os imperativos de segurança nacional e relevante interesse coletivo. Referidos requisitos têm de ser interpretados como um amálgama, um todo, e não por partes.

A ação direta do Estado na economia é objeto de estudo do Direito Institucional Econômico, através da organização da Administração Pública indireta, com a criação de entidades para administrar a atividade econômica, a partir da criação de pessoas jurídicas.

\subsection{A intervenção indireta}


A ação indireta do Estado no domínio econômico é defensiva, de efeitos mediatos. Traduz a ideia de Estado regulador, em que observa incentivos, fiscalização e planejamento da atividade econômica. Nela, o Estado irá intervir no domínio econômico através de normas como, por exemplo, a Lei $n^{\circ} 8.078 / 1990$, também denominada Código de Defesa do Consumidor.

A Constituição da República de 1988 também trata da ação indireta do Estado no domínio econômico, em seu art. 174, caput, ao afirmar que "como agente normativo e regulador da atividade econômica, o Estado exercerá, na forma da lei, as funções de fiscalização, incentivo e planejamento, sendo este determinante para o setor público e indicativo para o setor privado" (BRASIL, 1988).

Em plano infraconstitucional, observa-se a Lei Federal $n^{\circ}$ 8.031, de 1990, denominada Plano Nacional de Desestatização, como marco na redução da intervenção do Estado no domínio econômico. A intervenção estatal no domínio econômico reduz-se, no Brasil, a partir da privatização de empresas públicas que atuam no mercado que não requerem o estabelecimento de marco regulatório específico, como fertilizantes, petroquímica e siderurgia.

A ação indireta do Estado no domínio econômico é objeto de estudo do Direito Regulamentador Econômico, em que se produz um conjunto de normas, como circulares, decretos e portarias, para a política econômica de uma dada atividade econômica como, por exemplo, o marco regulatório das águas. Cria-se a legislação para o Poder Público e a Iniciativa Privada seguirem.

\subsection{A intervenção híbrida}

O fenômeno da ação híbrida do Estado no domínio econômico é recente. Traduz a ideia atual das agências reguladoras. Denomina-se híbrida por que, em um primeiro momento, o Estado age diretamente no domínio econômico ao criar uma autarquia especial, a agência reguladora. A normatização feita pelo ente regulador em seu domínio econômico é forma de ação indireta estatal na economia.

\subsubsection{As agências reguladoras}

As agências reguladoras são pessoas jurídicas que regulam determinado setor da economia. Possuem forma jurídica de autarquia em regime especial, vinculadas e não subordinadas a um respectivo Ministério. 
Faz-se imprescindível construir um conceito de autarquia para o correto prosseguimento deste estudo. O Decreto-Lei $n^{\circ}$ 6.016/1943 determinava que seria "serviço estatal descentralizado, com personalidade de direito público, implícita ou explicitamente criada por lei”" (BRASIL, 1943). Já o Decreto-Lei no 200/1967: “serviço autônomo criado por lei, com personalidade jurídica, patrimônio e receitas próprias, para executar atividades típicas da administração pública que requeiram, para seu melhor funcionamento, gestão administrativa e financeira descentralizada" (BRASIL, 1967). Este último é o conceito que ainda está em vigor. Por fim mais um detalhe. Parte dos teóricos do Direito brasileiro considera a Caixa Econômica Federal como a primeira autarquia instituída no Brasil, no ano de 1861.

As principais características de uma agência reguladora é que, geralmente, são autarquias federais especiais, fazem parte da Administração Pública Indireta, possuem autonomia administrativa e financeira e são independentes, pois, como já aqui afirmado são vinculadas a um Ministério e não subordinadas.

A importância de se criar uma agência reguladora pode ser expressa em 04 (quatro) motivos. O primeiro, e mais importante, é a necessidade de permanente monitoramento do mercado, devido a custos irreparáveis elevados, além de circunstâncias propícias a um comportamento oportunista. Elas irão atuar em esferas econômicas que possuem demanda por conhecimento de elevado grau de especialização. Os entes reguladores emitem, sistematicamente, normatização de sua área de atuação. Por fim, referidas entidades solucionam litígios frequentemente, de forma célere.

Feitas todas essas considerações, passa-se a uma análise do Sistema Financeiro Nacional (SFN), seu conceito e a legislação aplicável.

\section{DO SISTEMA FINANCEIRO NACIONAL}

O Sistema Financeiro Nacional é o mais importante setor da economia brasileira. Nele se concentra o maior poder decisório no que se refere ao campo econômico. É composto por duas autoridades monetárias, o Conselho Monetário Nacional e o Banco Central; três bancos públicos, o Banco Nacional de Desenvolvimento Econômico e Social (BNDES), Banco do Brasil (BB) e Caixa Econômica Federal (CEF); além de instituições financeiras.

\subsection{Legislação aplicável}


Tamanha importância é observada a partir da constitucionalização do assunto, o que faz inferir que o constituinte originário já demandava atenção ao referido setor. José Afonso da Silva afirma existirem dois sistemas financeiros regulados pela Constituição de 1988:

\begin{abstract}
Há dois sistemas financeiros regulados na Constituição: o público, que envolve os problemas das finanças públicas e os orçamentos públicos, constantes dos arts. 163 a 169; e o parapúblico, que ela denomina de sistema financeiro nacional, que cuida das instituições financeiras creditícias, públicas ou privadas, de seguro, previdência (privada) e capitalização, todas sob estrito controle do Poder Público (art. 192). O banco central, que é instituição financeira, constitui, em verdade, um elo entre as duas ordens financeiras (arts. 164 e 192) (SILVA, 2006, p. 824).
\end{abstract}

A interpretação do art. 192, da Constituição de 1988, suscitava algumas dúvidas. Estas foram sanadas com a promulgação da Emenda Constitucional n ${ }^{\circ}$ 40, de 29 de Maio de 2003. Todos os incisos e parágrafos de referido artigo, transferindo para seu caput toda a disciplina do setor.

\footnotetext{
A EC-40, de 29.5.2003, alterou profundamente o art. 192 da Constituição, eliminando todos os incisos e parágrafos. Transferiu para o caput do artigo a disciplina relativa à participação do capital estrangeiro nas instituições financeiras, que constava do inc. III, mas sem os condicionamentos que se previa nas alíneas $a$ e $b$ do inciso; passou também para o caput a previsão de disciplina das cooperativas de crédito, que figurava no inc. VIII. Com a eliminação dos parágrafos, a questão dos limites dos juros a $12 \%$, que figurava no $\S 3^{\circ}$, desapareceu do texto constitucional (SILVA, 2006, p. 824).
}

Outro ponto questionado era a regulação do Sistema Financeiro Nacional por meio de lei complementar. A dúvida era se seria somente uma lei complementar. A Emenda Constitucional sanou referida dúvidas ao empregar a expressão leis complementares. Porém, segue-se a teoria de José Afonso da Silva, que afirma que a expressão no singular não tinha sentido de unicidade, mas de generalidade.

Toda reforma em referido sistema terá de ser feito por meio de leis complementares, seguindo o preceituado no art. 69 da Constituição da República de 1988. Ressalte-se que aqui se trata de relações institucionais entre o Poder Público e as instituições financeiras, tanto públicas quanto privadas. Sobre as relações entre usuários e instituições financeiras, aplicamse o conjunto normativo próprio. Isso significa “[...] que não há razão alguma que justifique a pretensão de exclusão da incidência do Código de Defesa do Consumidor nas relações negociais entre bancos e clientela" (SILVA, 2006, p. 826). 
Não foi a Constituição da República de 1988 que instituiu o Sistema Financeiro Nacional. Ele já possuía uma estrutura legislativa infraconstitucional, que foi recepcionada com status de leis complementares: a Lei $n^{\circ} 4.595 / 1964$ e a Lei ${ }^{\circ} 4.380 / 1964$, esta última disciplina o Sistema Financeiro de Habitação.

Por fim, outros diplomas legais que tratam do SFN. A Lei $n^{\circ} 4.728 / 1965$, que disciplina o mercado de capitais e seu desenvolvimento; a Lei $\mathrm{n}^{\circ} 6.024 / 1974$, que trata da intervenção e liquidação extrajudicial das instituições financeiras; a Lei $n^{\circ}$ 6.045/1974, que reestrutura a constituição e as competências do CMN; a Lei $n^{\circ} 6.385 / 1976$, que cria a Comissão de Valores Mobiliários e disciplina referido mercado; a Lei n 6.404/1976, que trata das sociedades por ações e Lei $\mathrm{n}^{\circ} 7.450 / 1985$, que altera a legislação tributária federal.

\subsection{Os objetivos da Constituição de 1988}

O objetivo precípuo da Constituição da República de 1988 em relação ao Sistema Financeiro Nacional era estrutura-lo para a promoção do desenvolvimento equilibrado e, concomitantemente, servir aos interesses da sociedade, aqui vista de forma holística, como um todo. Seus componentes têm suas ações limitadas pela função social. Assim, “[...] as instituições financeiras privadas ficam assim, também, e de modo muito preciso, vinculadas ao cumprimento de funções sociais bem caracterizadas" (SILVA, 2006, p. 826).

\subsubsection{Duas polêmicas presentes na Constituição de 1988}

A promulgação da Emenda Constitucional n 40/ 2003 trouxe nova interpretação para duas polêmicas presentes na redação original da Constituição de 1988. A primeira trata da participação de capital estrangeiro nas instituições financeiras. Sobre esse assunto, José Afonso da Silva assim se manifesta:

\footnotetext{
As leis complementares (uma delas pelo menos) disporão sobre a participação do capital estrangeiro nas instituições que integram o sistema financeiro nacional, tendo em vista, especialmente, a promoção do desenvolvimento equilibrado do País e o interesse coletivo (SILVA, 2006, p. 826).
}

Outro ponto controverso presente na Constituição no que se refere ao Sistema Financeiro Nacional são as cooperativas de crédito. José Afonso da Silva afirma que:

O inc. VIII do art. 192, na redação primitiva, estatuía que a lei complementar teria também que dispor sobre o funcionamento das cooperativas de crédito e os 
requisitos para que pudessem ter condições de operacionalidade e estruturação próprias das instituições financeiras. A EC-40/ 2003, revogando aquele inciso, determinou, no entanto, que as leis complementares que dispuserem sobre o sistema financeiro nacional devem abranger também as cooperativas de crédito, e nada mais (SILVA, 2006, p. 827).

Feita toda essa reconstrução legislativa do Sistema Financeiro Nacional, precipuamente no que se refere à Constituição da República de 1988 busca-se explicar como referido sistema se transformou no mais importante da Economia brasileira.

\subsection{As migrações econômicas}

O Sistema Financeiro Nacional chegou à condição de mais importante de toda a Economia nacional devido ao fenômeno denominado migrações econômicas. Trata-se da realização de um conjunto de planos econômicos. Estes articularão políticas econômicas privadas e públicas com o objetivo de favorecer um determinado domínio econômico.

No Brasil, o setor financeiro foi o mais favorecido em detrimento a outras searas econômicas. Com isso, quase todo o setor produtivo necessita do SFN por causa do capital de giro e capital de investimento. Exceto as grandes empresas, incluídas ai as sociedades anônimas (SA).

Para o regular funcionamento do Sistema Financeiro Nacional, a Lei $n^{\circ} 4595 / 1964$ impôs duas autoridades monetárias para a regulação. O Conselho Monetário Nacional (CMN) possui função diretiva. É o órgão que irá normatizar todo o setor financeiro. Já o Banco Central (BACEN) tem função regulatória, principalmente no que se refere à físcalização do cumprimento das determinações do CMN. Mas também possui outras funções, que serão detalhadas adiante.

\section{DO BANCO CENTRAL DO BRASIL (BACEN)}

O objetivo deste capítulo é conceituar o Banco Central do Brasil, analisar suas características e, principalmente, tentar responder à primeira polêmica deste artigo: é o BACEN uma agência reguladora?

\subsection{Conceito e características do Banco Central do Brasil}

O Banco Central do Brasil é o aperfeiçoamento da antiga Superintendência da Moeda e do Crédito. Segundo o art. $2^{\circ}$, da Lei $n^{\circ} 4.595 / 1964$, referida autarquia é um dos componentes do Sistema Financeiro Nacional. Com isso, uma primeira afirmação já pode ser 
concretizada. O BACEN é uma autarquia federal. Portanto, é uma entidade que faz parte da Administração Indireta. Além disso, a Lei $n^{\circ} 4.595 / 1964$ o instituiu com patrimônio e personalidade jurídica próprias.

A Diretoria do BACEN, de acordo com o art. 84, XIV, da Constituição da República de 1988 é nomeada pela Presidência da República. Faz-se necessária a aprovação pelo Senado Federal. Mas não qualquer preceito constitucional ou infraconstitucional que obrigue o Chefe do Executivo comunicar a exoneração de determinado Diretor ao Legislativo (Congresso Nacional).

O art. 164, da Constituição de 1988, impõe a determinação de que compete à União a emissão de moedas, exercício esse exclusivo do Banco Central. Poderá também exercer compra e venda de títulos de emissão do Tesouro Nacional, tendo como objetivo precípuo a regulação de oferta de moeda ou da taxa de juros. Porém, não concederá, de forma direta ou indireta, empréstimos ao Tesouro Nacional ou a qualquer componente da Administração Pública, a não ser que seja instituição financeira.

As competências da autoridade monetária em comento estão elencadas nos arts. $8^{\circ}$ a $16^{\circ}$ da Lei $n^{\circ} 4.595 / 1964$. De forma objetiva, ele exerce as funções de controle e regulação do SFN. Porém, as competências do BACEN não estão previstas somente na Lei n 4.595/1964. A Lei $n^{\circ}$ 6.024/1974 estabelece a competência para intervenção em instituições financeiras nos casos previstos por ela.

Feita essas primeiras considerações sobre o BACEN, suscita-se: é referida autoridade monetária uma agência reguladora? Tentar-se-á responder a essa questão no próximo tópico.

\subsection{O Banco Central é uma agência reguladora?}

Visto que o Banco Central é uma entidade governamental (autarquia federal), parte da Administração Indireta, com patrimônio e personalidade jurídicas próprias, e que ele atua com a função de regular o sistema financeiro, surge a ideia de que é uma agência reguladora do setor bancário.

Fernando Herren Aguillar segue determinada corrente teórica de que é o "[...] caso de instituições que não têm denominação de agências reguladoras, mas exercem funções similares a elas. É o caso do Banco Central do Brasil, que tem funções reguladoras normativas e operacionais no setor financeiro" (AGUILLAR, 2014, p. 229). O teórico reconhece que a autoridade monetária é dotada de poder regulatório, no domínio econômico bancário. 
Mas é Gesner Oliveira e João Grandino Rodas (2004) que, de forma incisiva, afirmam que o Banco Central do Brasil não é uma agência reguladora. Ambos fundamentam seu pensamento no argumento de que referida autoridade monetária não se reveste de características marcantes dos entes reguladores, que no Brasil foram criadas na segunda metade da década de 1990 em diante.

\begin{abstract}
As agências reguladoras disciplinam o comportamento dos agentes econômicos em um primeiro momento por meio da edição de normas gerais (regulação) e, em um segundo momento, através da aplicação dessas normas a casos concretos, em que é julgada a conduta de uma empresa ou de um grupo determinado de agentes econômicos.

É por esta razão que se costuma dizer que as agências reguladoras exercem uma função quase legislativa e uma função quase judiciária, o que leva às críticas daqueles que acreditam serem essas prerrogativas exclusivas, respectivamente, do Poder Legislativo e do Poder Judiciário. (OLIVEIRA; RODAS, 2004, p. 134-135).
\end{abstract}

Assim, pode-se afirmar que o Banco Central do Brasil possui o poder regulatório do setor bancário brasileiro. Mas não é uma agência reguladora. Em primeiro lugar, por que a lei $\mathrm{n}^{\circ}$ 4.595/ 1964, que o instituiu não o denomina assim. Em segundo lugar, e mais importante, é que ele não possui caracteres marcantes de um ente regulador.

Apresentados esses subsídios teóricos para o debate sobre o Banco Central ser ou não um ente regulador passa-se para a mais tensa discussão: a autonomia da autoridade monetária em comento.

\title{
5 AUTONOMIA OU INDEPENDÊNCIA DO BANCO CENTRAL
}

O debate sobre a autonomia, ou independência, do Banco Central adquiriu novos contornos com os debates políticos-eleitorais do Brasil em 2014. Os primórdios de referida discussão iniciou-se a partir da promulgação da lei n ${ }^{\circ}$ 8.880/ 1994, denominada Programa de Estabilização Econômica.

Duas correntes teóricas estão envolvidas diretamente nesse debate. Os denominados monetaristas argumentam que o BACEN tem como função exclusiva a garantia da estabilidade monetária. Já os desenvolvimentistas afirmam que o Banco Central é um suporte às políticas econômicas criadas para o desenvolvimento econômico do País. Eliacir Marques Pereira critica essa visão reduzida do BACEN:

Condenamos o descontrole monetário, de triste memória em nosso País, porém somos de opinião que a política monetária não deve se constituir num fim em si mesma. O Banco Central deve ter a responsabilidade e a capacidade para formular e 
executar política monetária restritiva ou expansionista, segundo a conjuntura prevalecente, e de acordo com os objetivos e as metas fixadas pela política econômica (PEREIRA, 2003).

Feitas essas primeiras considerações passa-se a analisar se se trata de autonomia ou independência do Banco Central. A imprecisão conceitual na utilização dos termos em âmbitos econômico e financeiro faz com que analistas e políticos os considerem termos sinônimos. Eliacir Marques Pereira utiliza os ensinamentos de Jairo Saddi para fazer a distinção entre ambos as expressões:

\begin{abstract}
Autonomia [...] pressupõe a ideia composta de direção própria, de agir ou deixar de agir, de possuir a faculdade de organização, administrativa e juridicamente. A noção de autonomia pode ser expressa também como a direção própria daquilo que é próprio. Já a independência, é uma faculdade incondicional, não hierárquica, caracterizada pela não subordinação recíproca entre aqueles que exercem o poder; não sofre interferências, influências ou ingerências de outros elementos externos e tem assegurada legalmente suas atribuições de formas privativas e exclusivas. Um banco central independente puro é aquele que pode propor e implementar qualquer política monetária sem discussões prévias com o Executivo, o Legislativo ou qualquer outro grupo de interesse. Assim, a independência pressupõe a autosuficiência absoluta, enquanto a autonomia é apenas uma faculdade dada a um órgão da administração (SADDI apud PEREIRA, 2003).
\end{abstract}

Pela explicação dada, somente as Três Funções do Estado (Executivo, Legislativo e Jurisdicional) são independentes em sentido estrito. Então a discussão se passa em torno da autonomia administrativa do Banco Central.

\title{
5.1 Os argumentos utilizados pelas correntes teóricas no debate
}

Já foi mencionado aqui que a autonomia do Banco Central envolve dois grupos, os monetaristas e os desenvolvimentistas. Passa-se, agora, a análise dos argumentos utilizados por ambas as correntes para fundamentar seu posicionamento teórico.

\subsubsection{Argumentos favoráveis}

Citado por Eliacir Marques Pereira, o economista Roberto Luís Troster afirma que um Banco Central autônomo, imune à pressões políticas e tentações políticas conjunturais permite um combate de maior eficiência à inflação. Isto por que ele observa que há alguns setores políticos complacentes com a elevação das taxas inflacionárias devido a popularidade imediata. Mas referido teórico-econômico afirma que a autonomia administrativa do BACEN deve ser prevista em lei, de texto complexo, visto que terá de prever: 
[...] a responsabilidade por definir a meta de inflação; a decisão sobre como alcançar a meta; a capacidade econômico-patrimonial de operar os instrumentos financeiros; a autonomia orçamentária; a transparência; a governança; as relações do Banco Central com outras instituições; e a diretoria (TROSTER apud PEREIRA, 2003).

O fundamento utilizado por outro economista, Gustavo Loyola, é de que a importância de um Banco Central autônomo, formalmente, é de que isso traz credibilidade para investidores em âmbito internacional (LOYOLA apud PEREIRA, 2003).

Os principais fundamentos dos argumentos utilizados por monetaristas são o combate à inflação e credibilidade internacional. Ou seja, reafirmam a função exclusiva do Banco Central em garantir a estabilidade monetária.

\subsubsection{Argumentos contrários}

A economista Maria Cristina Penido de Freitas, citada por Eliacir Marques Pereira, argumenta de que a função exclusiva do BACEN em garantir a estabilidade monetária esgotou-se no início dos anos 2000, pois referida autoridade já agia com autonomia a partir da adoção do regime de metas de inflação (FREITAS apud PEREIRA, 2003).

Já para o economista Paulo Nogueira Batista Jr. (BATISTA JR. apud PEREIRA, 2003) afirma que a autonomia do Banco Central deve ser analisada com certas ressalvas. Isto por que a relação entre referida autoridade monetária e instituições financeiras privadas estariam eivadas de conluios. É o denominado caso de captura do regulador pelos regulados. A mera troca de dirigentes da autarquia pelo Presidente da República é um frágil contraataque à hegemonia dos interesses de instituições financeiras privadas.

Para os teóricos contrários à tese de autonomia administrativa formal do Banco Central, ela já existe concretamente. Há frágeis instrumentos utilizados pelo governo para tentar combater os conluios da autoridade monetária em sua relação com as instituições financeiras, principalmente as da Iniciativa Privada.

\section{CONCLUSÕES}

O assunto Banco Central do Brasil merece um refinamento em seus estudos. Não pode ficar como mera especulação em meio a debates político-econômicos. Referida autoridade monetária exerce função precípua no mais importante setor da Economia brasileira, o Sistema Financeiro Nacional. 
Trata-se de uma autarquia federal, dotada de poderes regulatórios no domínio econômico bancário, mas não é uma agência reguladora, pois não se reveste das principais e mais importantes características de tal.

Em relação à sua autonomia faz-se necessário uma ampliação do debate. Relacionar sua autonomia administrativa-formal a garantir estabilidade monetária ou instrumentalizá-lo como forma de desenvolvimento econômico diminui seu papel na condução da política econômica.

Infelizmente, o assunto parece estar fadado ao esquecimento da política nacional. Como já afirmado faz-se, de extrema importância, discussões refinadas sobre o tema, com intensa participação da sociedade civil organizada. Assim, busca-se a confirmar a posição do Banco Central como legítima Autoridade Monetária.

\section{REFERÊNCIAS}

AGUILLAR, Fernando Herren. Direito Econômico: do direito nacional ao direito supranacional. $4^{\mathrm{a}}$ ed. São Paulo: Atlas, 2014,

BRASIL. Constituição (1988). Constituição da República Federativa do Brasil de 1988. Disponível em:

http://www.planalto.gov.br/ccivil_03/constituicao/ConstituicaoCompilado.htm. Acesso em: 19 nov. 2014.

BRASIL. Decreto-Lei n⿳ 200, de 25 de fevereiro de 1967. Dispõe sôbre a organização da Administração Federal, estabelece diretrizes para a Reforma Administrativa e dá outras providências. Disponível em: http://www.planalto.gov.br/ccivil_03/decreto-lei/del0200.htm. Acesso em: 19 nov 2014.

BRASIL. Decreto-Lei no 6.016, de 22 de novembro de 1943. Dispõe sobre a imunidade dos bens, rendas e serviços das autarquias, e dá outras providências. Disponível em:

http://www2.camara.leg.br/legin/fed/declei/1940-1949/decreto-lei-6016-22-novembro-1943416115-publicacaooriginal-1-pe.html. Acesso em: 19 nov. 2014.

FONSECA, João Bosco Leopoldino da. Direito Econômico. Rio de Janeiro: Forense, 2010.

O'ROURKE, P. J. A riqueza das nações de Adam Smith: uma biografia. Tradução de Roberto Franco Valente. Rio de Janeiro: Jorge Zahar, 2008.

PEREIRA, Eliacir Marques. Autonomia do Banco central - subsídios para discussão.

Maio/2003. Disponível em: http://www2.camara.leg.br/documentos-epesquisa/publicacoes/estnottec/tema12/pdf/301964.pdf. Acesso em: 20 nov. 2014. 
SILVA, José Afonso. Curso de Direito Constitucional Positivo. 26ª ed. rev. São Paulo: Malheiros, 2006.

SOUZA, Washington Albino Peluso de. Primeiras Linhas de Direito Econômico. $5^{\text {a }}$ ed. São Paulo: LTr, 2003.

SOUZA, Washington Albino Peluso de. Teoria da constituição econômica. Belo Horizonte: Del Rey, 2002.

GOMES, Luiz Souza. Dicionário econômico-comercial e financeiro. $7^{\mathrm{a}}$ ed. Rio de Janeiro: Civilização brasileira S.A., 1962.

OLIVEIRA, Gesner; RODAS, João Grandino. Direito e economia da concorrência. Rio de Janeiro: Renovar, 2004. 